\title{
Study on Poly(3,4-ethylenedioxythiophene) Thin Film Vapour Phase-Polymerized with Iron(III)Tosylate on High Quality 3-Aminopropyltriethoxysilane Self-Assembled Monolayer
}

\author{
Sangil Choi, Wondae Kim, Sung Jun Cho, and Sungsoo Kim ${ }^{\dagger}$
}

\begin{abstract}
In this study, PEDOT thin films polymerized with Iron(III)tosylate (Fe(PTS) $)_{3}$ and grown on atomically smooth and highly dense 3-aminopropyltriethoxysilane self-assembled monolayer (APS-SAM) surfaces by VPP method have been investigated. PEDOT thin films were synthesized on APS self-assembled $\mathrm{SiO}_{2}$ wafer surface at two different concentrations ( $20 \mathrm{wt} \%$ and $40 \mathrm{wt} \%$ ) and growth time ( 3 and 30 minutes), and then their sheet resistance were measured and compared. PEDOT thin films grown with $20 \mathrm{wt} \% \mathrm{Fe}(\mathrm{PTS})_{3}$ oxidant are highly conductive when compared with the film grown with $40 \mathrm{wt} \% \mathrm{Fe}(\mathrm{PTS})_{3}$, as ascertained by the measured sheet resistance values down to $0.06 \Omega / \mathrm{cm}$. It clearly suggests that $20 \mathrm{wt} \%$ is more effective oxidant concentration for VPP than $40 \mathrm{wt} \%$ even though the film grown with $40 \mathrm{wt} \%$ oxidant has better quality than the film with $20 \mathrm{wt} \% \mathrm{Fe}(\mathrm{PTS})_{3}$ does.
\end{abstract}

Key words: Poly(3,4-ethylenedioxythiophene), 3-Aminopropyltriethoxysilane, Vapor Phase Polymerization, Iron(III)tosylate

\section{Introduction}

For decades, conductive $\pi$-conjugated polymers have fascinated many scientists with their great potential for applicability to the next-generation flexible display device such as organic thin film transistors (OTFTs) and organic light emitting diodes (OLEDs) ${ }^{[1]}$. Among these polymers, poly(3,4-ethylenedioxythiophene) (PEDOT) has been particularly focused on as a potential component of OTFT or OLED devices due to its superb material characteristics ${ }^{[2]}$. PEDOT is electrochemically very stable, and it has a low bandgap energy $(1.5 \sim 1.7 \mathrm{eV})$ and a considerably high electrical conductivity. PEDOT thin film is generally synthesized via two different methods, i.e., spin-coating or oxidative vapour phase polymerization (VPP). Electrical characteristics of the thin film prepared by those methods are critically affected by its growth morphology. In particular, our recent study showed that the morphology of PEDOT thin film polymerized with $\mathrm{FeCl}_{3}$ and grown on a high

'Department of Nano-Polymer Materials Engineering,Pai Chai University, Daejeon, 302-735

${ }^{\dagger}$ Corresponding author : skim@pcu.ac.kr

(Received: December 10, 2012, Revised: December 15, 2012, Accepted : December 21, 2012) quality 3-amonopropyltriethoxythiophene self-assembled monolayer (APS-SAM) is noticeably different from that of the thin film grown on a relatively low quality APS-SAM ${ }^{[3]}$. The film grown on the high quality SAM by vapour phase polymerization (VPP) method is denser (or less porous) and more robustly adhered to silicon oxide surface. It suggests that APSSAM helps to improve the PEDOT film quality, thereby improving the electrical characteristics of the film. It means that the film morphology is considerably affected by APS-SAM, itself as well as its quality. Therefore, in this study, in order to improve electrical characteristics of PEDOT thin film vapour phase-polymerized and then doped with $\mathrm{Fe}$ (para-toluenesulfonate $)_{3}\left(\mathrm{Fe}(\mathrm{PTS})_{3}\right)$, the thin films were grown on two differently prepared (both high and low quality) APS-SAMs, and then they were compared in terms of oxidant concentration and growth time.

\section{Experimental Section}

Chemicals used in this experiment and pre-cleaning process of oxidized Si-wafer $(1.5 \mathrm{~cm} \times 1.5 \mathrm{~cm})$ were described in the first section of these serial publications. APS self-assembled monolayer was prepared in a glove 


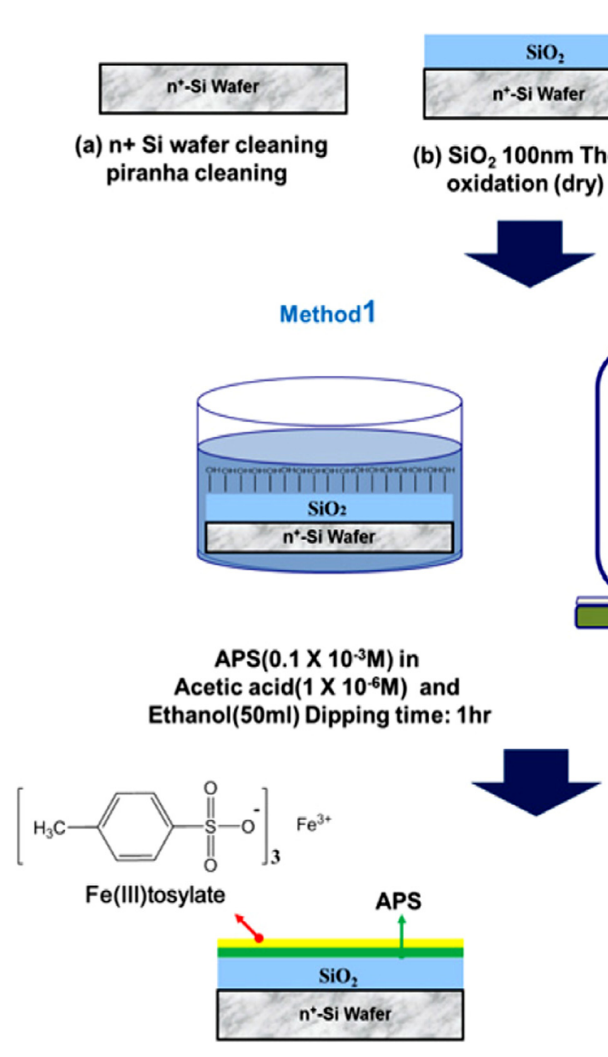

(d) $\mathrm{Fe}$ (III)tosylate spin coating
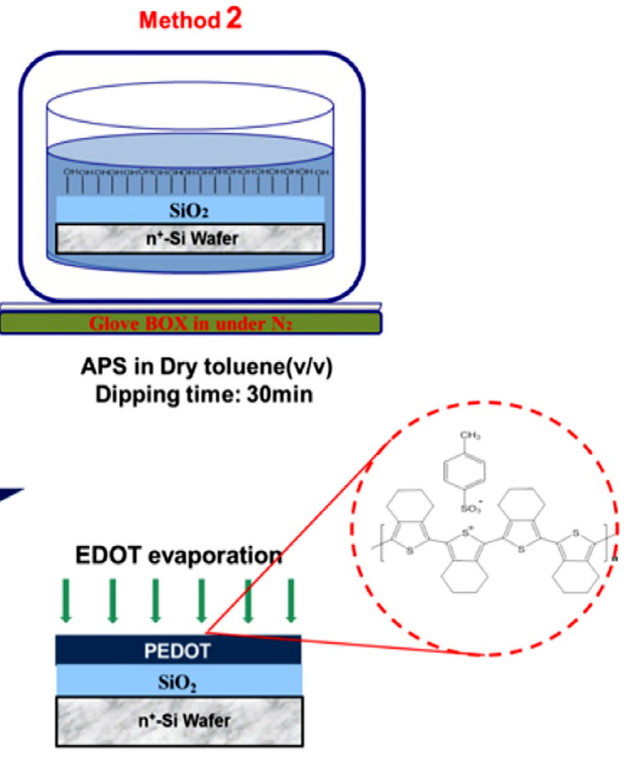

(f) PEDOT deposition

Fig. 1. Schematic diagram of PEDOT vapour phase polymerization (VPP) method. Fe(PTS $)_{3}$ was used as a dopant as well as an oxidant for the VPP process.

box under a strictly controlled humidity $(<10 \% \mathrm{RH})$. And also completely anhydrous toluene was used as a solvent throughout the preparation. The cleaned wafer substrate was dipped into APS $(120 \mu \mathrm{L})$ solution dissolved in $60 \mathrm{~mL}$ of anhydrous toluene for 30 minutes. Two different oxidant solutions for the growth of PEDOT thin film were prepared with $20 \mathrm{wt} \%$ and $40 \mathrm{wt} \%$ Iron(III)Tosylate $6 \mathrm{H}_{2} \mathrm{O}$ dissolved in ethanol. Oxidant films were spin-coated on the wafer substrates at $2500 \mathrm{rpm}$ for 90 seconds. And then, as shown in Fig. 1 , PEDOT was vapor phase-polymerized in an oven at $70^{\circ} \mathrm{C}$ for 3 and 30 minutes, respectively. In order to characterize APS-SAM and PEDOT thin film, AFM (VEECO, Nanoman, U.S.A) and FE-SEM (FEI, Sirion model, Netherlands) were used, and sheet resistance of PEDOT thin film were measured using a 4-point probe (A.I.T, CMT-SR2000).

\section{Results and Discussion}

Our previous study showed that the growth morphology and interfacial adhesion of PEDOT thin film is highly dependent upon APS-SAM ${ }^{[3]}$. That is, APSSAM helps $\mathrm{FeCl}_{3}$ solution to uniformly coat $\mathrm{SiO}_{2}$ surface and also to promote adhesion between PEDOT thin film and $\mathrm{Si}$ wafer substrate, thereby resulting in improved film quality. PEDOT thin film is vapour phase-polymerized generally via two different oxidants, i.e., $\mathrm{FeCl}_{3}$ and $\mathrm{Fe}(\mathrm{PTS})_{3}$. Both oxidant have their own merits. However, unlike $\mathrm{FeCl}_{3}, \mathrm{Fe}(\mathrm{PTS})_{3}$ is more advantageous to the deposition of less porous film. Thus, as the second part of these serial publications, PEDOT thin films polymerized with the $\mathrm{Fe}(\mathrm{PTS})_{3}$ oxidant and grown on high quality APS-SAMs by VPP method have been mainly investigated. Fig. 2 shows FE-SEM images of PEDOT thin films grown on atomically smooth and 


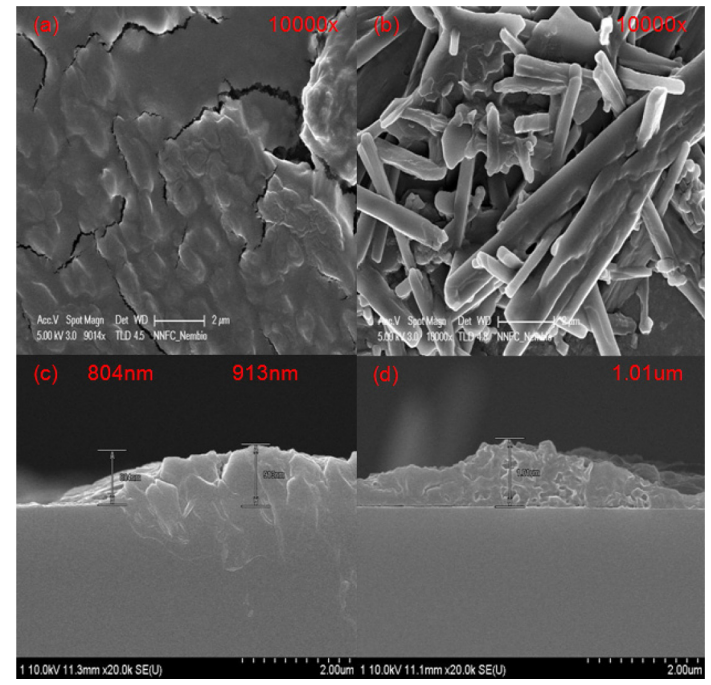

Fig. 2. FE-SEM images of PEDOT thin films grown on atomically smooth and highly dense APS-SAMs. All of the films used $20 \mathrm{wt} \% \mathrm{Fe}(\mathrm{PTS})_{3}$. The films in (a) and (c) images were grown for 3 minutes and those in (b) and (d) images for 30 minutes.

highly dense, i.e., high quality APS-SAM surfaces via only $20 \mathrm{wt} \% \mathrm{Fe}(\mathrm{PTS})_{3}$. In general, it has been known that $40 \mathrm{wt} \% \mathrm{Fe}(\mathrm{PTS})_{3}$ is used for the synthesis of highly conductive VPP-PEDOT ${ }^{[4]}$. However, such concentration is too high for the oxidant to over-dominate the physico-chemical properties of the polymer, itself. Therefore, this study tried to reduce the concentration of $\mathrm{Fe}(\mathrm{PTS})_{3}$ to the half $(20 \mathrm{wt} \%)$ of currently known optimal one when a base inhibitor such as pyridine is used for the VPP reaction ${ }^{[4]}$. However, as shown in Fig. 2, PEDOT formed considerably rough films at both 3 and 30 minutes of growth time. Especially, at 3 minutes of the growth time, the film was rougher than at longer growth time of 30 minutes. In addition, at 30 minutes of the growth time, the film contained large and rodshaped crystals while, at shorter growth time, the film was thin and flaky. It suggests that the $20 \mathrm{wt} \%$ oxidant solution was not really well coated on the atomically smooth and dense high quality APS-SAM surface. ${ }^{[3]}$ As a result, PEDOT films quite roughly grew on the monolayer surface. In the case of $40 \mathrm{wt} \% \mathrm{Fe}(\mathrm{PTS})_{3}$, the film morphologies are quite different no matter which growth time is. First of all, they, both PEDOT, completely formed films as shown in Fig. 3. It points out that the oxidant solution was uniformly coated on the

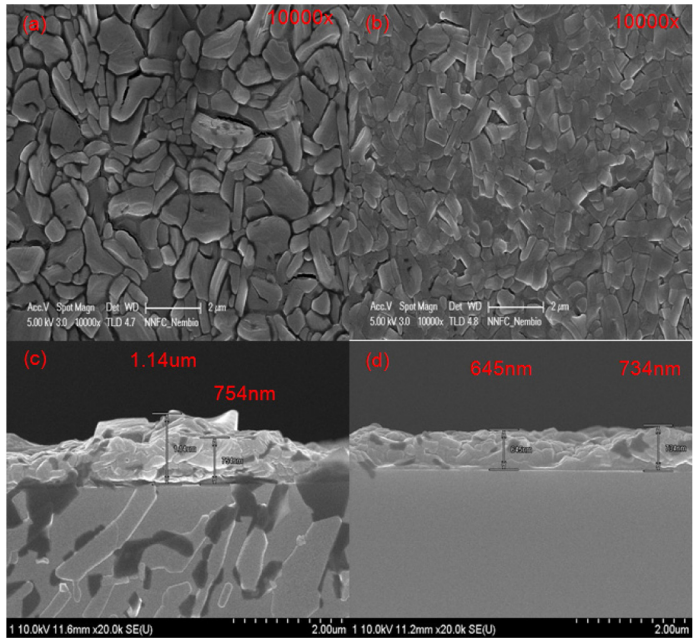

Fig. 3. FE-SEM images of PEDOT thin films grown on atomically smooth and highly dense APS-SAMs. All of the films used $40 \mathrm{wt} \% \mathrm{Fe}(\mathrm{PTS})_{3}$. The films in (a) and (c) images were grown for 3 minutes and those in (b) and (d) images for 30 minutes.

high quality APS-SAM surface. However, more interestingly, the texture of the film surface at shorter growth time are dramatically different from the one at $30 \mathrm{~min}$ utes of the growth time. The film grown for 3 minutes looks like isolated and disconnected crystal domains while the one grown for longer period looks like more flatten out and all of the domains became connected, which means that the cracks were filled with polymer or something else.

This study also measured sheet resistance of PEDOT thin films as shown in Table 1. According to the result, PEDOT thin films grown with $20 \mathrm{wt} \% \mathrm{Fe}(\mathrm{PTS})_{3}$ show more reliable and stable values than the films grown with $40 \mathrm{wt} \% \mathrm{Fe}(\mathrm{PTS})_{3}$. Surprisingly, this result is totally opposite from FE-SEM images. That is, the films grown with $20 \mathrm{wt} \%$ oxidant are electrically more conductive than the ones grown with $40 \mathrm{wt} \%$ oxidant. As shown in Table 1, some values in the case of $40 \mathrm{wt} \% \mathrm{Fe}(\mathrm{PTS})_{3}$ are too high, which strongly suggests that many crystalline domains are unlikely to be connected. Also, more importantly, the sheet resistance values of the film grown with $20 \mathrm{wt} \%$ oxidant are noticeably high, which range from $0.06 \Omega / \mathrm{cm}$ to $36.3 \Omega / \mathrm{cm}$. Table 1 shows the large difference of sheet resistance values between two films grown with $20 \mathrm{wt} \%$ and $40 \mathrm{wt} \%$ oxidants, respectively. Most reasonable explanation for this result is the 
Table 1. Sheet resistance values measured at three different positions of PEDOT thin films vapour phase-polymerized on atomically smooth and highly dense APS-SAM surfaces

\begin{tabular}{ccccc}
\hline & \multicolumn{2}{c}{$\begin{array}{c}20 \mathrm{wt} \% \text { Fe(PTS) })_{3} \text {-PEDOT } \\
\text { on APS-SAM }\end{array}$} & \multicolumn{2}{c}{$\begin{array}{c}40 \mathrm{wt} \% \text { Fe(PTS })_{3} \text {-PEDOT } \\
\text { on APS-SAM }\end{array}$} \\
\hline GrowthTime & $3 \mathrm{~min}$ & $30 \mathrm{~min}$ & $3 \mathrm{~min}$ & $30 \mathrm{~min}$ \\
\hline Position & \multicolumn{4}{c}{ Sheet Resistance $(\Omega / \mathrm{cm})$} \\
2 & 30.1 & 0.06 & 9.83 & 8,939 \\
3 & 36.3 & 31.3 & too high & 23.5 \\
& 34.1 & 35.7 & too high & too high \\
\hline
\end{tabular}

difference in the degree of conjugation of PEDOT backbones. The $40 \mathrm{wt} \%$ concentration is too high for the oxidant to effectively polymerize EDOT monomers since its $\mathrm{pH}$ is too low $(\sim 1)$. Such low $\mathrm{pH}$ solution can very easily drive unwanted side reactions besides the polymerization. Therefore, relatively low concentration of $20 \mathrm{wt} \%$ oxidant, giving rise to a higher $\mathrm{pH}$, might suppress unwanted side reactions but polymerization. More detail spectroscopic and adhesion studies are underway.

\section{Summary}

This study showed that PEDOT thin films grown with $20 \mathrm{wt} \% \mathrm{Fe}(\mathrm{PTS})_{3}$ oxidant are highly conductive when compared with the film grown with $40 \mathrm{wt} \%$ $\mathrm{Fe}(\mathrm{PTS})_{3}$, as ascertained by the measured sheet resistance values. It clearly suggests that $20 \mathrm{wt} \%$ is more effective oxidant concentration for VPP than $40 \mathrm{wt} \%$ even though the film grown with $40 \mathrm{wt} \%$ oxidant has better quality than the film with $20 \mathrm{wt} \% \mathrm{Fe}(\mathrm{PTS})_{3}$ does.

\section{Acknowledgment}

This study was financially supported by Flexolution Corporation, Yongin, Korea.

\section{References}

[1] K. Kaneto, M. Maxfield, D. P.Nairns, A. G. MacDiarmid, and A. J. Heeger, "Electrochemistry of polyacetylene, $(\mathrm{CH}) \mathrm{x}$, characteristics of polyacetylene cathodes", J. Chem. Soc., Faraday Trans. 1, Vol. 78, pp. 3417-3429, 1982.

[2] G. Gustafsson, Y. Cao, G. M. Tracy, F. Klavetter, N. Colaneri, and A. J. Heeger, "Flexible light-emitting diodes made from soluble conducting polymers", Nature, Vol. 357, pp. 477-479, 1993.

[3] S. Choi, W. Kim, and S. Kim, "Development of highly conductive poly(3,4-ethylenedioxythiophene) thin film using high quality 3 -aminopropyltriethoxysilane self-assembled monolayer", J. Chosun Natural Sci., Vol. 4, pp. 294-297, 2011.

[4] B. Winther-Jensen, D. W. Breiby, and K West, "Base inhibited oxidative polymerization of 3,4-ethylenedioxythiophene with iron(III)tosylate", Synth. Metals, Vol. 152, pp. 1-4, 2005. 